\title{
Millennials and the use of social networking sites as a job searching tool
}

\author{
Zarina Denan, Zarina Abdul Munir, Nurul Hazzira Fadzil, Kardina Kamaruddin, \\ Mohd Redhuan Dzulkifli \\ Faculty of Business Management Universiti Teknologi MARA Cawangan Selangor, Kampus Puncak Alam, \\ 42300 Bandar Puncak Alam, Selangor, Malaysia
}

\begin{tabular}{|c|c|}
\hline Article Info & ABSTRACT \\
\hline Article history: & $\begin{array}{l}\text { This research is conducted to examine the factors that influence } \\
\text { the behavioural intention of millienials in using SNS when seeking for a job. }\end{array}$ \\
\hline Received Aug 21, 2019 & The data was collected from respondents who are from the generation \\
\hline Revised Oct 24, 2019 & Y demographic and actively looking for jobs. The respondents must possess \\
\hline Accepted Nov 30, 2019 & $\begin{array}{l}\text { some experience in using SNS when job hunting. The data was then gathered } \\
\text { and analyzed using partial least square (PLS) which encompasses }\end{array}$ \\
\hline Keywords: & $\begin{array}{l}\text { the measurement and structural models of the study. The findings revealed } \\
\text { that three of the constructs as applied in TAM are statistically significant }\end{array}$ \\
\hline Behaviouralintention & to behavioural intention. The three factors that influenced the job seekers' \\
\hline Gen Y & $\begin{array}{l}\text { intention to use SNSs as a job search tool are; perceived usefulness, } \\
\text { perceived ease of use and privacy concerns. All these factors are elements }\end{array}$ \\
\hline Perceive usefulness & which contribute to and have a significant relationship with job seekers' \\
\hline Perceived ease of use & intention to use SNSs, as verified using PLS data analysis. The recruiters \\
\hline Privacy concerns & or employers who intend to adopt SNSs in the recruitment process \\
\hline Social networking & are advised to design the recruitment plan regarding the utilization of SNSs \\
\hline $\begin{array}{l}\text { Theory of technology } \\
\text { acceptance }\end{array}$ & $\begin{array}{l}\text { to be more convenient and user-friendly. This study provides insight } \\
\text { and knowledge regarding the impact of technology in online job application } \\
\text { and hiring processes. }\end{array}$ \\
\hline
\end{tabular}

This is an open access article under the CC BY-SA license.

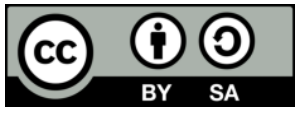

Corresponding Author:

Zarina Denan,

Faculty of Business Management,

Universiti Teknologi MARA Cawangan Selangor,

Kampus Puncak Alam, 42300 Bandar Puncak Alam, Selangor, Malaysia .

Email: ZarinaDenan2516@outlook.com

\section{INTRODUCTION}

Recruitment is a crucial component of the human resource management (HRM) department in any organization. Recruitment involves seeking out, engaging and assessing potentialemployees suited to various roles within the organization. It is tremendously difficult to discover and obtain such candidates, and this requires human resource (HR) managers to apply different tactics in the efforts to recruit workers. These days, recruitment processes can be conducted conventionally or through e-recruitment systems, which function through information technology tools. Conventional rec ruitment approaches include putting advertisements in newspapers regarding vacant positions, utilizing executive search firms, and engaging recruitment agencies which refer relevant employees to the organization [1-5]. The development of technology has enabled all these methods to be carried out via e-recruitment or other Internet-based job application services. 
The age of e-recruitment has significantly changed the recruitment process as a whole. However, older recruitment approaches should not be discarded entirely, but used in ways that complement electronic-based methods. According to Kaur new technology must not fully replace traditional processes, which can function to compensate for the flaws of electronic systems and foster a quick and effective recruitment process [6].

Social networking sites (SNSs) are among the most popular online platforms in current times. It is extensively utilized by HR managers and job seekers due to its convenience and efficiency. One can use SNSs in order to seek out a vailable vacancies in organizations, particularly through career-centric sites like LinkedIn [7]. The organization can also reach a wide range of potentialemployees with various qualifications and competencies [8]. Additionally, with well-structured and organized processes, SNSs can aid a firm in saving expenses and ensuring that the recruitment approach is less time-consuming, by cutting down on the period needed for processing information [9]. In order to enhance the quality of the job applications, it is presumed that someone who utilizes e-recruitment options is already computer literate and capable of working with new technology.

The yearly worldwide survey, the Kelly Global Workforce Index (KGWI), is conducted by the renowned recruitment firm, Kelly Services, and referred to in a report in the Malay Mail. This survey discovered that Malaysians rank far above the regional average rate in terms of individuals using SNSs as a platform for job seeking, as opposed to traditional methods. This encompasses 67 per cent of the total number of 5,147 respondents. Additionally, 62 per cent of respondents also described being approached with offers for vacant positions on social networking sites, and another 28 per cent also claim that the job offers eventually led to successful employment.

Despite this, in [10] asserts that SNSs cannot be an effective method for recruitment processes because it does nothing to enhance the recruiter's powers of judgement and discernment. Kilpatrick also argues that SNSs as a platform is not capable of facilitating the huge number of relationships between potentialemployees and employers. Reiners proposes that the success of SNSs in the recruitment process can be achieved by ensuring that everyone involved is aware of the social dynamics in creating and engaging with social media profiles. As such, the concept of the technology acceptance model (TAM) is adopted as the foundation used in order to better comprehend the function of social networking sites as recruitment aids. The researcher explores elements including ease of use, perceived usefulness, and issues regarding privacy. Thus, the objective of the current study is to examine the intentions of generation Y to utilize SNSs as a job seeking tool.

\section{METHODOLOGY}

Data was gathered from 188 respondents who are part of generation Y and are in the process of looking for work. The respondents must have a degree of experience in utilizing SNS within their job search efforts. The instrument for perceived ease of use and perceived usefulness were derived from [11-15]. Other items such as privacy concerns were derived while behavioural intention was derived from [16]. The items were tested through a five point Likert scale where $1=$ strongly disagree and $5=$ strongly agree. The data was gathered and analyzed through partial least square (PLS) which examines the structural model and measurement model of the study.

\section{RESULTS AND DISCUSSION}

\subsection{Measurement model}

Convergent validity describes the extent to which multiple items are capable of measuring the same concept. In [17] states that the evaluation of a measurement model involves composite reliability (CR), factor loadings, and average variance extracted (AVE). This is shown in Table 1. The acceptable value for loadings must exceed 0.5 while the CR must be over 0.7. Based on the results, the eight items of behavioral intention $(\mathrm{CR}=0.891, \mathrm{AVE}=0.541)$, four items of perceived ease of use $(\mathrm{CR}=0.808, \mathrm{AVE}=0.517)$, four items of privacy concerns $(\mathrm{CR}=0.801, \mathrm{AVE}=0.503)$, and four items of perceived usefulness $(\mathrm{CR}=0.891$, $\mathrm{AVE}=0.541$ ) all exhibit that the values of factor loading, composite reliability and AVE exceeded the acceptable values. Some items were removed as a result of low factor loading. These are the items EOU2, EOU3, EOU6 and EOU7, four items of privacy1, privacy2, privacy 4, privacy5, and one item of BI1.

After verifying the convergent validity, the process to evaluate the discriminant validity using the [18] approach was carried out. Amin, Thurasamy, Aldakhil and Kaswuri explain discriminant validity as the item which differentiates between constructs, and is applied to testing items through the process of comparing the AVE with squared correlations values, or comparing the square root of the AVE with correlations values. The correlation values in the diagonal sections must exceed the values within 
the columns and rows of that construct. When these conditions are met, the measures can be considered discriminant. Table 2 shows the difference in correlation values among the constructs, which were discovered to exceed the values of the row and column. As such, the data in this study was cleared of any problems related to discriminant validity. Figure 1 shows measurement model.

Table 1. Convergent validity

\begin{tabular}{ccccc}
\hline Constructs & Items & Outer Loading & Composite Reliability & Average VarianceExtracted(AVE) \\
\hline \multirow{5}{*}{ Behavioral Intention } & BI_1 & 0.83 & 0.891 & 0.541 \\
& BI_2 & 0.779 & & \\
& BI_3 & 0.638 & & \\
& BI_4 & 0.709 & & \\
& BI_5 & 0.648 & & \\
& BI_6 & 0.715 & 0.517 & \\
& BI_8 & 0.808 & & \\
& EOU_1 & 0.642 & 0.808 & \\
Perceived Ease of Use & EOU_4 & 0.803 & & \\
& EOU_5 & 0.607 & 0.801 & \\
& EOU_8 & 0.8 & & \\
& Privacy_3 & 0.698 & & \\
& Privacy_6 & 0.819 & & \\
& Privacy_7 & 0.641 & & \\
& Privacy_8 & 0.666 & & \\
& Useful_1 & 0.596 & & \\
& Useful_2 & 0.782 & & \\
& Useful_3 & 0.746 & & \\
& Useful_4 & 0.639 & & \\
& Useful_5 & 0.726 & & \\
& Useful_6 & 0.536 & & \\
& Useful_7 & 0.806 & & \\
& Useful_8 & 0.792 & & \\
\hline
\end{tabular}

** Items deleted EOU2, EOU3, EOU6, EOU7, privacy1, privacy2, privacy4, privacy5, BI1 due to lower factor loading

Table 2. Discriminant validity

\begin{tabular}{lcccc}
\hline Constructs & 1 & 2 & 3 & 4 \\
\hline 1.Behavioral Intention & $\mathbf{0 . 7 3 6}$ & & & \\
2.Perceived Ease of Use & 0.656 & $\mathbf{0 . 7 1 9}$ & & \\
3.Perceived Us efulness & 0.567 & 0.466 & $\mathbf{0 . 7 0 9}$ & \\
4.Privacy Concerns & 0.285 & 0.182 & 0.23 & $\mathbf{0 . 7 0 9}$ \\
\hline
\end{tabular}

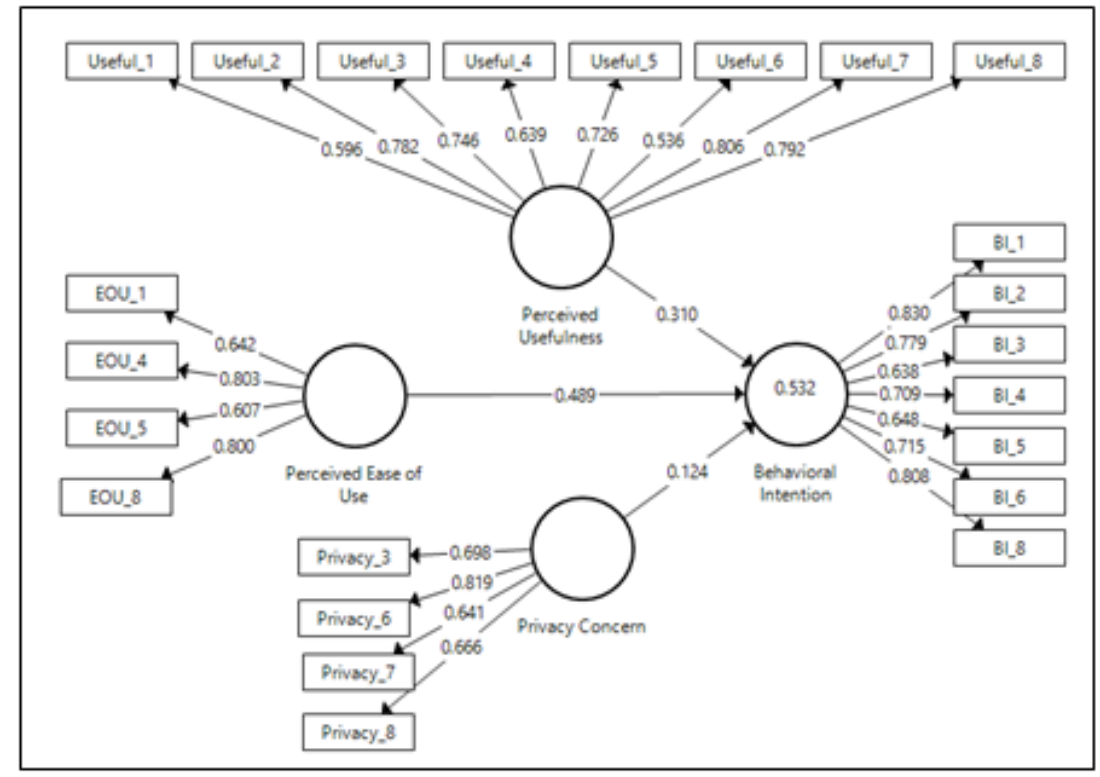

Figure 1. Mea surement model 


\subsection{Structural model}

In the structural model, the value of $\mathrm{R}$ square is 0.532 which represents how 53.2 percent of behavioural intention among the job seekers can be accounted by perceived ease of use, perceived usefulness and privacy concerns. The beta coefficient in this research has indicated that there is a positive relationship between perceived ease of use $(\beta=0.489$, std $=0.054)$, perceived usefulness $(\beta=0.310, \operatorname{std}=0.069)$ and privacy concerns $(\beta=0.124$, std $=0.047)$. Additionally, the beta values revealed that only privacy concern s had a low relationship with behavioural intention (as the beta values are lower than 0.1) whereas perceived of ease and perceived usefulness were moderately correlated to behavioural intention. More analysis was conducted to investigate the significance of the relationship, examine the t-values results and perform bootstrapping procedures on 500 samples. The t-values must exceed 1.96 where significance values must be under 0.01 . Table 3 shows that perceived ease of use $(t=9.111, \mathrm{p}<0.01)$, perceived usefulness $(\mathrm{t}=4.484$, $\mathrm{p}<0.01)$ and privacy concerns $(\mathrm{t}=2.625, \mathrm{p}<0.01)$ are statistically significant in relation to behavioural intention. In addition to that, perceived ease of use was found to be in a medium effect $\left(\mathrm{f}^{2}=0.396\right)$, while low effect is reflected in perceived usefulness $\left(f^{2}=0.156\right)$, and privacy concerns $(0.031)$, which are in alignment with the recommendations from Cohen. Thus, hypothesis 1, hypothesis 2 and hypothesis 3 were supported for this study. Figure 2 shows structural model.

Table 3. Structural validity

\begin{tabular}{|c|c|c|c|c|c|c|c|}
\hline Relationship & $\begin{array}{c}\text { Standard } \\
\text { Beta }\end{array}$ & $\begin{array}{c}\text { Standard } \\
\text { Error }\end{array}$ & T-values & P Values & F Square & LL & UL \\
\hline Perceived Ease of Use -> Behavioral Intention & 0.489 & 0.054 & 9.111 & $\mathrm{p}<0.01$ & 0.396 & 0.382 & 0.615 \\
\hline Privacy Concerns -> Behavioral Intention & 0.124 & 0.047 & 2.625 & $\mathrm{p}<0.01$ & 0.031 & 0.047 & 0.212 \\
\hline
\end{tabular}

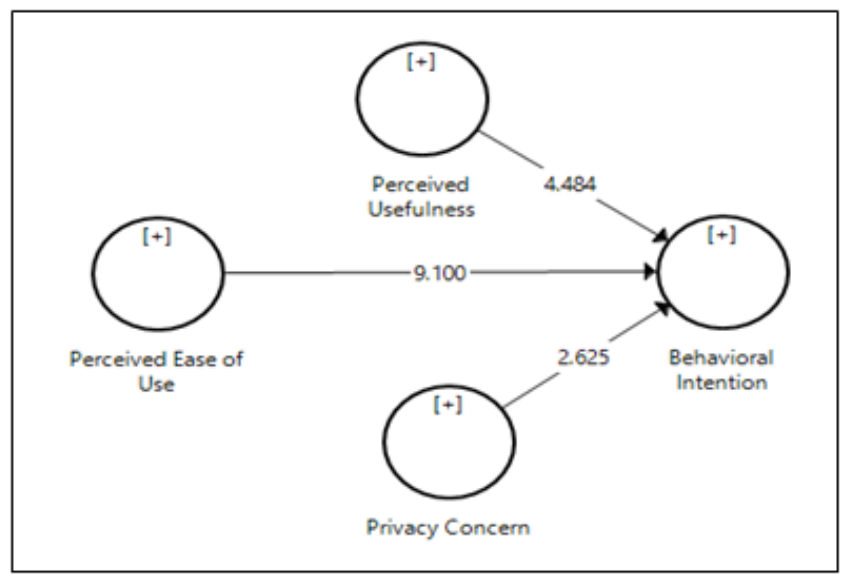

Figure 2. Structural model

The findings also indicate that the users consider the content, form and functionality of the websites to be convenient and ea sily comprehended. This is attributed to how simple the sites are to navigate and how promptly users are able to find relevant information or perform necessary tasks. Finally, the degree of control held by the users when utilizing a website or app also contributes to its usability. Comparative studies conducted highlighted that a considerable amount of existing research which adopted the TAM model discovered a positive relationship between perceived ease of use and the individual behavioural intention to utilize a system or application. This is consistent with the results discussed above.

In terms of privacy concerns, the low effect results are attributed to the possibility that employers using SNSs as a recruitment platform will be capable of accessing applicants' social media profiles in an effort to screen them or gather more information. This can happen when applications are reviewed and employers seek out the candidates' profiles. This poses a risk to employment in the case where recruiters may decide that some information they have found reveals the applicant to be an unsuitable selection. However, access to knowledge regarding the applicants' values and attachments to various social and professional groups can assist recruiters in discerning whether or not the candidate is a good match for the job position and the organization as a whole [18-25]. 


\section{CONCLUSION}

This study has expanded on existing research regarding online consumer behaviourby incorporating online recruitment tools into its scope. The study investigated the factors which impact the intention of job seekers to utilize SNSs as a platform to access work opportunities. The assessments in this study are contingent upon the TAM established by Davis in 1986. The three factors which influenced the job seekers' intention to utilize SNSs as a job seeking tool are perceived ease of use, perceived usefulness, and privacy concerns. Each factor has been verified as a meaningfulcomponent in job seekers' intention to utilize SNSs, and have significant relationships with job seekers' intention as validated by PLS data analysis.

In terms of the implications of this study, employers who intend to incorporate SNSs in the recruitment process must ensure that the design is convenient and any applications involved are easy to use. For example, employers should include links to job applications on SNSs which link to the organization's corporate page. This ensures that potential candidates can quickly and conveniently submit an application. The recruiters or employers can also incorporate interactive elements in SNSs so that potential candidates for the positions are able to conduct discussions or ask questions directly to representatives from the recruiting party. Finally, an organization intending to utilize SNSs in the recruitment process must establish policies which dictate the ethics and guidelines related to screening and social engagement with potential employees through the Internet. This process should begin with increasing the organization's knowledge regarding social networking. It is suggested that employees involved in recruitment be given relevant training. In this way information gathered in the recruitment process will be managed more responsibly and precisely. Organizations should also make the effort to keep the company's sites and pages up-to-date so that any information or questions from candidates can be handled quickly and efficiently.

Job seekers should take the initiative to ensure that their SNS accounts are free of information or content which they would not want a potentialrecruiter to see. These include personal information, photos and status updates or comments. Job seekers should also ensure that the personal information they choose to feature on SNS is accurate and updated. It is also suggested that they make connections and network with various online communities relevant to their field. Suggestions and recommendations from contacts on sites such as LinkedIn can also be a good resource for references regarding job vacancies and opportunities. The study findings indicate that the issue of privacy is concerning to many job seekers. The organization must be careful in cases where job applications are submitted online. The employees involved in recruitment must undergo the relevant training and education. This is imperative for establishing confidence and sincerity in the relationship between both parties during the recruitment process, and can result in the best possible outcomes for the hiring organization and its potentialemployees.

\section{ACKNOWLEDGEMENTS}

This research was supported by BESTARI Grant of Universiti Teknologi MARA, Malaysia (BESTARI 600-IRMI/SSP/DANA 5/3/BESTARI (00025/2016).

\section{REFERENCES}

[1] N. Allden, and L. Harris, "Building a positive candidate experience: Towards a networked model of e-recruitment," Journal of Business Strategy, vol. 34, no. 5, pp. 36-47, 2013.

[2] J. Cohen, "Statistical power analysis for the behavioral sciences," Hillsdale, NJ: Lawrence Erlbaum, 1988.

[3] F. D. Davis, "Perceived usefulness, perceived ease of use, and user acceptance of information technology," MIS Quarterly, vol. 13, no. 3, pp. 319-340, 1989.

[4] R. Doherty, "Getting social with recruitment," Strategic HR Review, vol. 9, no. 6, pp. 11-15, 2010.

[5] M. Fishbein, and I. Ajzen, "Belief, attitude, intention and behavior: An introduction to theory and research," Massachusetts: Addison-Wesley Publishing Company, 1975.

[6] C. Fornell, and D. F. Larcker, "Evaluating structural equation models with unobservable variables and measurement error," Journal of Marketing Research, vol. 18, no. 1, pp. 39-50, 1981.

[7] P. Guriting, and N. O. Ndubisi, "Borneo online banking: Evaluating customer perceptions and behavioural intention," Management Research News, Vol. 29, no. 1/2, pp. 6-15, 2006.

[8] J. F. Hair, W. C. Black, B. J. Babin, and R. E. Anderson, "Multivariate data analysis: A global perspective," New Jersey, Pearson Prentice Hall, 2010.

[9] P. Kaur, "E-recruitment: A conceptual study," International Journal of Applied Research, vol. 1, no. 8, pp. 78-82, 2015.

[10] R. Kilpatrick, "Social media - a panacea or recruitment?," The Structural Engineer, pp. 38-39, 2013.

[11] M. Amin, R. Thurasamy, A. M. Aldakhil, and A. H. B. Kaswuri, "The effect of market orientation as a mediating variable in the relationship between entrepreneurial orientation and SMEs performance," Nankai Business Review International, vol. 7, no. 1, pp. 39-59, 2016. 
[12] M. Plummer, "Job Seeking and Job Application in Social Networking Sites: Predicting Job Seekers' Behavioral Intentions, in Information Systems," New Jersey Institute of Technology, 2010.

[13] N. Rakholiya, and C. Gupta, "A study on the applicant's perception towards e-recruitment," International Multidisciplinary Journal of Applied Research, vol. 1, no. 1, pp. 50-53, 2013.

[14] T. Ramayah, Y. I. Chin, M. S. Norazah, and I. Amlus, "Determinants of intention to use an online bill payment system among MBA students," E-Business, vol. 9, pp. 80-91, 2005.

[15] T. A. Reiners, "Social network Perception Alignment of E-recruiters and Potential Applicants," 46th Hawaii International Conference on System Sciences, pp. 4576-4585, 2013.

[16] Social media the new job-hunting ground, survey show. from http://www.themalaymailonline.com/malaysia/article/social-media-the-new-job-hunting-ground-survey-shows. Date accesed: 02/11/2016

[17] P. Söyrilä, "Students' perceptions and usage of social media for job seeking in the hospitalitu industry," Thesis paper, Haaga-Helia University of Applied Sciences, 2012.

[18] J. M. Stopfer, and S. D. Gosling, Online Social Networks in the Work Context. In D. Derks \& A. Bakker (Eds.), "The psychology of digital media at work". London: Psychology Press, 2013.

[19] D. Mirabbasi, M. Parvin, H. Javid, "A Comparison of Several Approaches to Load Frequency Control of Multi Area Hydro-Thermal System," UCT Journal of Research in Science, Engineering and Technology, vol. 3, no. 4, pp. 24-30, 2015.

[20] V. Sakthive, P. V. Kesaven, J. Martin William, \& S. K. Madan Kumar, "Integrated platform and response system For healthcare using Alexa," International Journal of Communication and Computer Technologies, vol. 7, no. 1, pp, 14-22, 2019.

[21] Rauf, S., Kalim, I., \& Mubeen, M. Impact of Electronic Media on Pakistan's Security. Global Social Sciences Review,vol. III, no. I, pp. 434-446, 2018.

[22] Mukrimah Nawir, Amiza Amir, Naimah Yaakob, Ong Bi Lynn, "Effective and efficient network anomaly detection system using machine learning algorithm," Bulletin of Electrical Engineering and Informatics (BEEI), vol 8, no. 1, pp. 46-51, 2019.

[23] Siti Rohani Tajuddin, S. N. Azemi, P. J. Soh, C.B.M. Rashidi, A Abdullah Al-Hadi, "Analysis and design of directive antenna using frequency selective surface superstrate," Indonesian Journal of Electrical Engineering and Computer Science (IJEECS), vol. 14, no. 2, 529-536, 2019.

[24] M. Saleem, F. A. Khan, \& A. Zaman, "Wh-Movement Pattern in the Spoken Discourse of Teachers A Syntactic Analysis," Global Social Sciences Review, vol. III, no. II, pp. 400-420, 2018.

[25] C. Carreto, D. Gêgo, \& L. Figueiredo, "An Eye-gaze Tracking System for Teleoperation of a Mobile Robot," Journal of Information Systems Engineering \& Management, vol. 3, no. 2, pp. 16, 2018. 